\title{
MACH ONE SPEED AUTOMOTIVE ENGINE (M1SAE)
}

\author{
Ronauk Kumar Maharana ${ }^{1}$ \\ ${ }^{I}$ B. Tech, Mechanical Engineering, College of Engineering and Technology, Bhubaneswar, Odisha, India
}

\begin{abstract}
An automobile engine is specially designed to liberate a particular amount of power at a required speed that in turn drives the automobile. Unlike the jet engines, whose main purpose is to provide thrust, the main purpose of the automotive engine is to produce torque which is required to run the automobile on ground. Higher is the torque lesser becomes the speed. Fighter jets equipped with turbojet engines can go fast enough to cross the sound barrier and can travel beyond mach one speed. But in case of automobiles it is quite impossible. Since a high torque is required to run the vehicle on ground the speed decreases. But keeping the required amount of torque constant if the power delivered by the engine can be increased beyond maximum the speed of the vehicle will increase. So, a special type of engine can be designed using suitable materials and calculated values that can drive a vehicle beyond mach one speed with the required amount of torque on ground called the Mach One Speed Automotive Engine (MISAE).
\end{abstract}

Keywords - Engine, Mach one speed, Power, Torque, Speed, Cylinder, Piston, Connecting Rod, Crankshaft, Engine Operations

\section{INTRODUCTION}

The main objective is to design the basic components of an automobile engine in order to make the engine produce enough power such that at the top gear the automobile will run at mach one i.e. the speed of sound in vacuum $(340 \mathrm{~m} / \mathrm{s})$. Internal combustion engines are those heat engines that convert chemical energy of combustion inside the cylinder into mechanical energy. An I.C. engine develops torque and power to run an automobile. They are of two types; petrol and diesel. Petrol engines are generally used for light load operations where as diesel engines are used for heavy load operations. Many sports cars consist of petrol engines. The main components of a petrol engine or SI engine are cylinder, crankcase, piston, piston rings, connecting rod, crankshaft, flywheel, valves, rocker arm and camshaft. These components are designed using different processes and parameters based upon strength, efficiency, applications, etc.

\section{THEORY}

The main purpose of an engine is to generate power. There lies a relationship between power, torque and the speed of the engine i.e.

$$
\mathrm{P}=\frac{2 \pi \mathrm{NT}}{60}
$$

Where,

$\mathrm{P}=$ Power developed by the engine

$\mathrm{N}=$ Speed of crankshaft (RPM)

$\mathrm{T}=$ Torque required to drive the vehicle
So, if two of the parameters are known to us then we can find the third parameter. For the purpose of designing, we need to know the power that can be developed by the engine.

Most of the sports car possesses petrol engines because of anti-knocking properties at high speeds. For the M1SAE engine we also choose to design a petrol engine. We know that the output speed required is 340 metres per second i.e. the speed of sound in vacuum. We know the relation between power (P), force $(\mathrm{F})$ and velocity (v) is $\mathrm{P}=\mathrm{Fv}$. A body moving with a force $\mathrm{F}$ has to apply an equal and opposite frictional force on the ground. An automobile has 4 wheels. Hence the force applied by each wheel is,

$$
F_{w}=F / 4
$$

The torque required by each wheel is $T=F_{w} \times R$ where $R$ is the radius of the wheel.

Assuming the wheel diameter to be $600 \mathrm{~mm}$, then $\mathrm{R}=$ $300 \mathrm{~mm}$, at the top speed of the vehicle i.e. when the speed ratio of gear box is 1:1 and then at that time let the speed of the wheels be N RPM, which is same as the speed of the engine. The angular speed of the wheel is given by,

$$
\mathrm{w}=\frac{2 \pi \mathrm{N}}{60} \quad \text { or } \quad \frac{\mathrm{v}}{\mathrm{R}}=\frac{2 \pi \mathrm{N}}{60}
$$


For a high speed sports car engine the torque required in general is of the order of $1500 \mathrm{Nm}$

Hence, the power required by the engine is given by,

$$
\begin{aligned}
P & =\frac{2 \pi N T}{60}=\frac{2 \pi \times 11000 \times 1500}{60}=1699.95 \mathrm{~kW} \\
& =1700 \mathrm{~kW}
\end{aligned}
$$

The resulting power is the brake horse power. Considering frictional and other losses, the net indicated power is $\mathrm{P}=$ $1800 \mathrm{~kW}$

Hence, we have to design such an engine that will be capable of generating a power of $1800 \mathrm{~kW}$ with a torque of $1500 \mathrm{Nm}$ and engine speed of 11000 RPM so that it will make the vehicle move at mach one speed on the top gear.

\section{NOMENCLATURE}

$\mathrm{S}_{\mathrm{ut}}=$ Ultimate tensile strength of material (MPa)

$\sigma_{\mathrm{t}}=$ Allowable tensile strength of material $(\mathrm{MPa})$

f.o.s. $=$ Factor of Safety

$\sigma_{\mathrm{R}}=$ Radial stress developed inside the cylinder (MPa)

$\mathrm{P}_{\mathrm{i}}=$ Internal gas pressure developed inside the cylinder (MPa)

$\mathrm{d}=$ Bore diameter of the cylinder $(\mathrm{mm})$

$\mathrm{L}=$ Stroke length $(\mathrm{mm})$

$\mathrm{P}=$ Power developed by the engine i.e. Indicated power $(\mathrm{kW})$

$\mathrm{N}=$ Number of power strokes in one cycle or number of rotations of crank shaft (RPM)

$\mathrm{t}=$ Thickness of cylinder $(\mathrm{mm})$

$\mathrm{t}_{1}=$ Thickness of piston head $(\mathrm{mm})$

$\mathrm{p}=$ Indicated mean effective pressure $(\mathrm{MPa})$

$\mathrm{A}=$ Area of cross section of piston $\left(\mathrm{mm}^{2}\right)$

$\mathrm{k}=$ Number of cylinders

$\mathrm{t}_{2}=$ Thickness of piston rib $(\mathrm{mm})$

$\mathrm{F}_{\mathrm{g}}=$ Load on connecting rod due to gas pressure $(\mathrm{N})$

$\mathrm{A}_{\mathrm{c}}=$ Area of cross section of connecting $\operatorname{rod}\left(\mathrm{mm}^{2}\right)$

$1=$ Effective length of connecting $\operatorname{rod}(\mathrm{mm})$

$\mathrm{E}=$ Young's modulus of the material $(\mathrm{GPa})$

$\mathrm{t}_{\mathrm{c}}=$ Thickness of connecting $\operatorname{rod}(\mathrm{mm})$

$\mathrm{H}=$ Height of connecting rod at mid section ( $\mathrm{mm}$ )

$\mathrm{d}_{1}=$ Diameter of piston pin $(\mathrm{mm})$

$\mathrm{P}_{\mathrm{b} 1}=$ Bearing pressure at piston pin $(\mathrm{MPa})$

$1_{1}=$ Length of piston pin $(\mathrm{mm})$ $\mathrm{d}_{2}=$ Diameter of crank pin $(\mathrm{mm})$

$\mathrm{P}_{\mathrm{b} 2}=$ Bearing pressure at crank pin $(\mathrm{MPa})$

$1_{2}=$ Length of crank pin $(\mathrm{mm})$

\section{ASSUMPTIONS AND CONSIDERATIONS}

The material required for designing of all engine parts is assumed to be homogeneous and isotropic. For the engine cylinder it is assumed that there are no residual stresses developed inside it. The thermal strength of piston material is assumed to be same as design strength. For the connecting rod it is assumed that both ends are hinged so that its effective length is same as the actual length of connecting rod. The bearings in the engine are assumed to be frictionless in nature.

We have considered the factor of safety of the material for all components to be 6 . The designs are done within their safety limits. Moreover the frictional and other losses of the engine are neglected. The generated power in the engine is considered to be the indicated power of the automotive engine.

\section{SELECTION OF MATERIAL}

The material for various major parts of the engine like cylinder, piston, etc. is taken to be Titanium (Ti) or more specifically Titanium alloys. Titanium is mostly used in case of manufacturing of parts for aircraft engines because of its light weight and higher strength. The ultimate tensile strength of Titanium is $620 \mathrm{MPa}$ and the yield strength is $480 \mathrm{MPa}$. It has a density of $4540 \mathrm{~kg} / \mathrm{m}^{3}$ which makes it lighter in weight with respect to its volume and a Young's modulus of 110 $\mathrm{GPa}$ thus increasing its strength. Its melting point is $1950 \mathrm{~K}$ which is higher than iron and steel alloys thus making it more advantageous to be used. However it is a bit expensive as compared to iron and steel alloys. Also it is not found everywhere in the world but at specific places. Titanium can be used in the manufacturing of M1SAE thus making the engine parts lighter as well as providing strength to the parts in order to withstand high power generation.

\section{DESIGN OF CYLINDER}

The engine cylinder is the most important part of the engine. The fuel is burnt inside the cylinder which in turn develops the power. The conversion of heat energy into mechanical energy takes place inside this. So the cylinder needs to be designed in order to withstand the high pressure and high temperature combustion. 


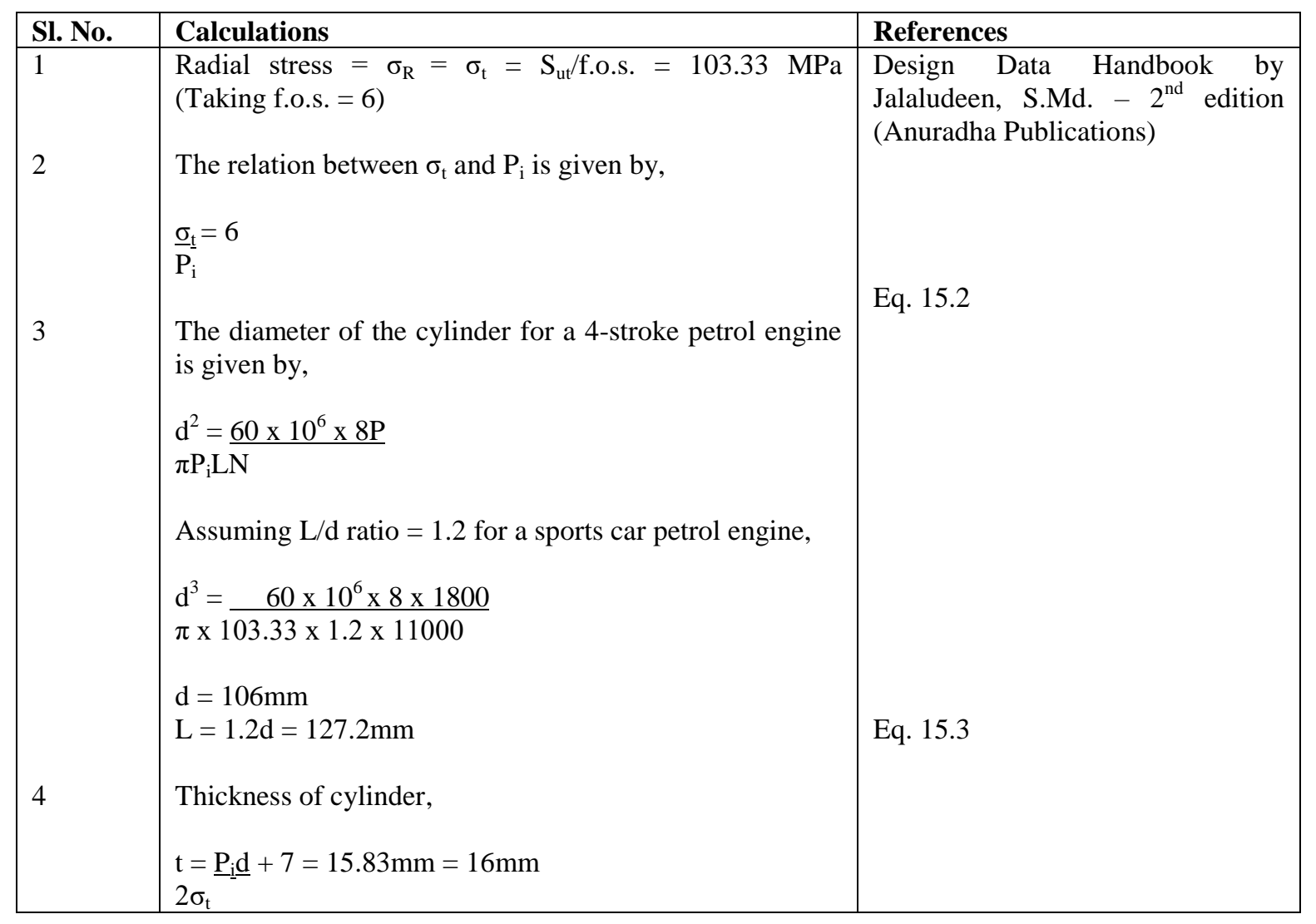

\section{DESIGN OF PISTON}

The piston is the reciprocating component of the engine. The power developed by the engine makes the piston reciprocate so as to transmit rotary motion. Hence the piston needs to be designed such that it will have a low weight inorder to decrease the effect of reciprocating masses

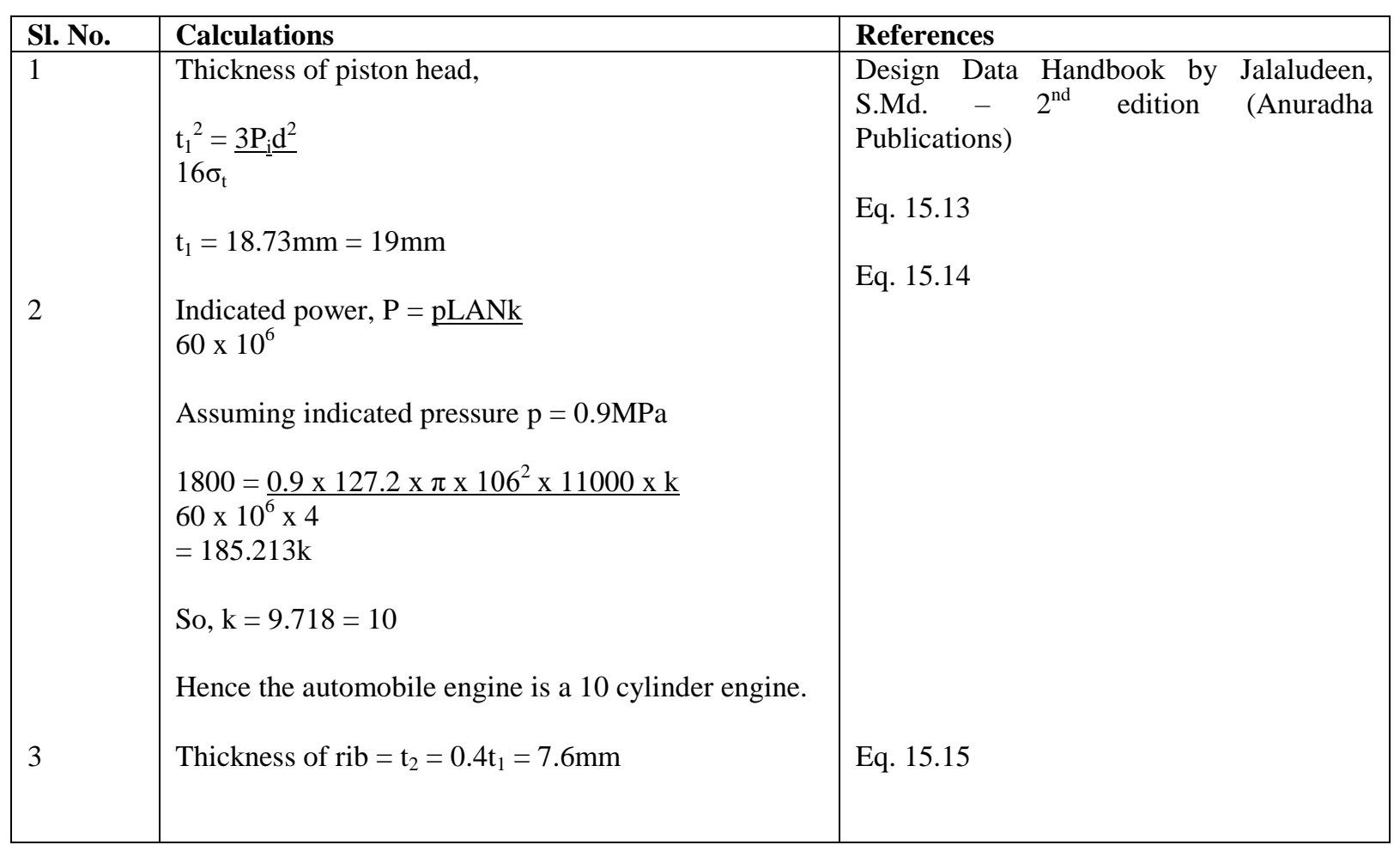




\section{DESIGN OF CONNECTING ROD}

The connecting rod transmits the reciprocating motion of piston into rotary motion of the crankshaft. So the connecting rod needs to be designed such that it should be strong enough to withstand bending effects.

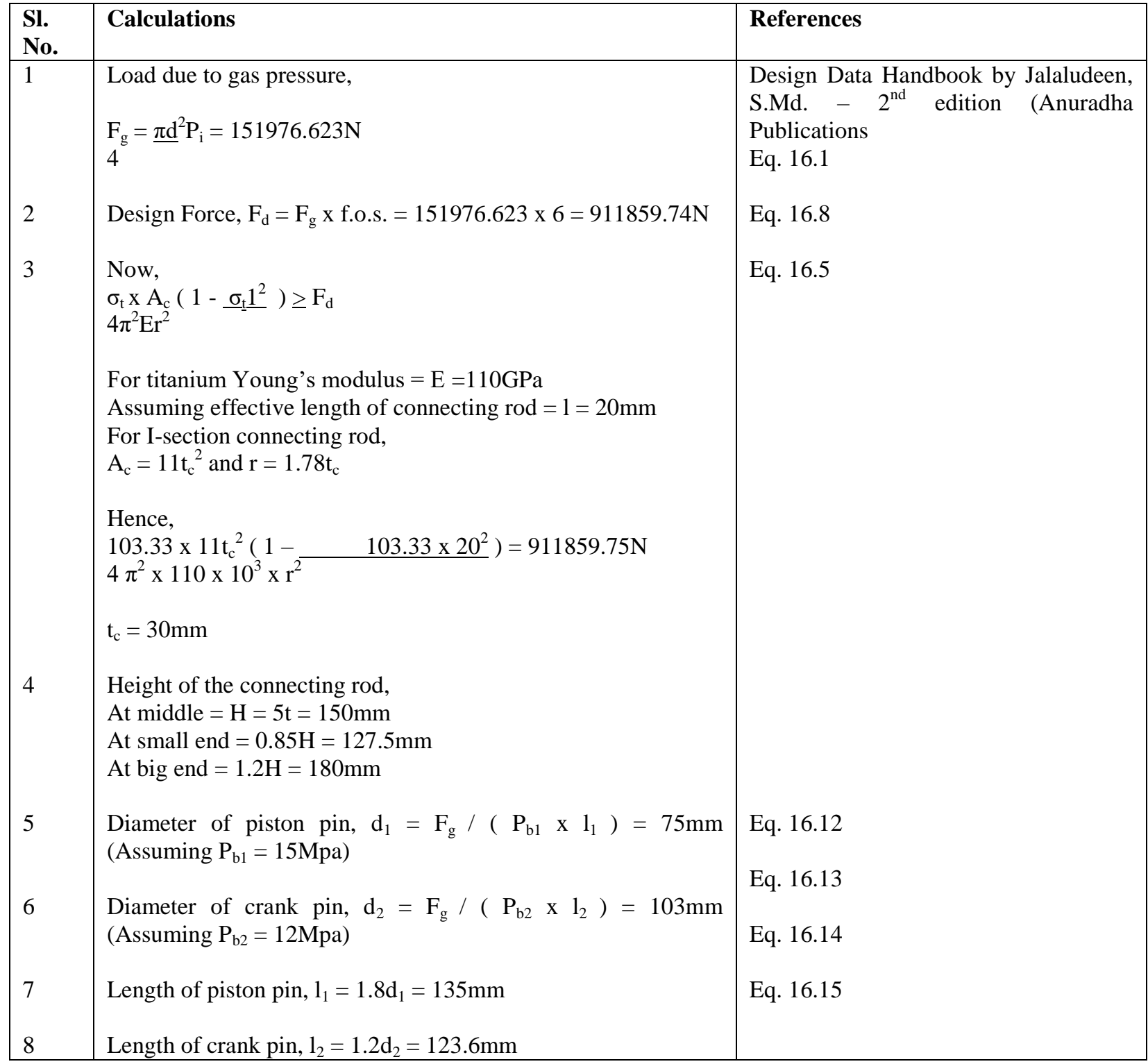

\section{MERITS AND DEMERITS}

The M1SAE engine can have a bright future ahead. It can be used to make commercial vehicles as well as can be used for making sports cars. This type of engine has not been made yet. Hence one can make the fastest car on earth by studying the design and manufacture of this engine. Since the material for various engine parts is taken as titanium there will be minimum inertia forces acting on the parts as well as they can withstand high power generated by the engine. So the engine is safe to be implemented in any automobile. The calculated dimensions are based upon theoretical analysis only. This engine can give us the fastest car on earth which can cross the sound barrier.

However titanium is expensive and not found everywhere in the world. Making the parts out of titanium or titanium alloys would make the engine expensive than other commercial engines. Thus it won't be affordable by everyone and only limited models could be provided. The engine needs a practical testing and analysis since the calculated dimensions are based upon theoretical analysis only. However the engine can be implemented in sports cars to suit the cost effectiveness.

\section{CONCLUSION}

The Mach One Speed Automotive engine (M1SAE) can be a unique piece of art. It can make history by being the first engine to run a car that can cross the sound barrier. The designs of various automotive engine parts are made within the safely limits and can be manufactured practically. Like the designs of the engine cylinder, piston and connecting rod 
other engine parts like the crankshaft, flywheel, etc. can also be designed similarly using the given data. Most of the calculations made are based upon assumptions and considered data. Hence the above calculated dimensions of various components are based upon theoretical analysis. However the M1SAE engine needs a practical verification of the calculations to come into existence and to be used practically. The necessary power could be generated by the engine at required torque to run the vehicle at 11000 RPM thus making the car run at the speed of Mach 1 and hence the fastest car on earth.

\section{REFERENCES}

[1]. S. Md. Jalaludeen “Design Data Handbook $-2^{\text {nd }}$ Edition": Anuradha Publications

[2]. R. B. Gupta “Automobile Engineering”: Tech India Publication Series by Satya Prakashan

[3]. V. Ganesan “Internal Combustion Engines”: McGraw Hill Education (India) Pvt. Ltd.

[4]. V. B. Bhandari "Design of Machine Components": McGraw Hill Education (India) Pvt. Ltd.

[5].https://en.wikipedia.org/wiki/Internal_combustion_engin

[6]. https://en.wikipedia.org/wiki/Mach_number

[7]. http://www.wartsila.com/energy/learningcenter/technical-comparisons/combustion-engine-for-powergeneration-introduction

[8].http://www.slideshare.net/yeswanthkumarreddy1/designof-engine-cylinders-and-pistons

\section{BIOGRAPHY}

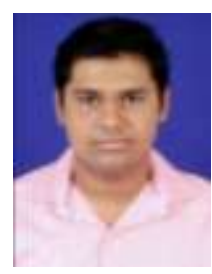

Ronauk Kumar Maharana is presently pursuing Bachelor in Technology degree in Mechanical Engineering from College of Engineering and Technology, Bhubaneswar, Odisha, India. He is an intern from Hindustan Aeronautics Ltd. Sukhoi Engine Division, Koraput, Odisha. $\mathrm{He}$ is a member of the Society of Automotive Engineers (SAE), India and presently Student Co-ordinator at SAE, CETBhubaneswar Chapter. He is also a technical core member at Zairza Robotics Society, The Technical Club of CETBhubaneswar. He has completed a design course in CATIA software from Central Tool Room and Training Centre, Bhubaneswar. He can be contacted through the email address: ronauk.india@gmail.com. 